revista ANTHROPOLÓGICAS

Ano 22, 29(2):154-187, 2018

\title{
Crime e Loucura: Estudo sobre a medida de segurança no Distrito Federal ${ }^{1}$
}

\author{
Érica Quinaglia Silva ${ }^{a}$ \\ Marília Calegari ${ }^{\mathrm{b}}$
}

\begin{abstract}
A medida de segurança é uma sanção penal aplicada a pessoas consideradas loucas e criminosas pela Justiça. A realização desta pesquisa quanti-qualitativa, mediante a análise de processos e prontuários, permitiu conhecer o perfil sócio-demográfico dessa população no Distrito Federal. 81\% eram solteiras, $85 \%$ eram negras, $61 \%$ tinham o Ensino Fundamental Incompleto e 45\% eram trabalhadoras dos serviços, vendedoras do comércio em lojas e mercados. Ademais, $27 \%$ tinham transtornos mentais e comportamentais devidos ao uso de álcool e outras drogas. Quanto aos crimes, $38 \%$ foram cometidos contra o patrimônio. Finalmente, $3 \%$ dessas pessoas tinham a data de extinção da sentença expirada. A noção de periculosidade associada a elas perpetua o enclausuramento em hospitais-presídios. Conhecê-las enseja desconstruir preconceitos e revisitar a política de saúde mental.

Crime, Loucura, Medida de Segurança, Reforma Psiquiátrica, Política de Saúde Mental.
\end{abstract}

\section{A história do conceito e a construção da loucura ${ }^{2}$}

A loucura é interior à razão, ou seja, sua concepção depende do entendimento histórico e social sobre o que vem a ser normalidade.

a Professora da Universidade de Brasília, Doutora em Sociologia, Demografia e Antropologia Social (Université Paris Descartes - Sorbonne). Email: equinaglia@yahoo.com.br. b Doutoranda e Mestra em Demografia (UNICAMP). Email: marilia_calegari@ yahoo.com.br. 
No entanto, embora este conceito seja cambiante, há algo que permanece imutável ao longo da história da loucura no Ocidente: o sentido da exclusão social (Foucault 2008; Frayze-Pereira 1994).

No Renascimento, havia o costume de confinar os loucos em barcos que se deslocavam nos rios da Renânia e dos canais flamengos, as naus dos loucos. Existia um sentido ritual nessa circulação de insanos: acreditava-se que a água, ao mesmo tempo que expulsava os loucos das cidades, os purificava (Foucault 2008; Frayze-Pereira 1994).

Essa segregação perdurou nos séculos XVII e XVIII, momento que ficou conhecido como 'a grande internação'. Nesse período, a loucura ganhou um endereço: fixou-se no hospital. Os hospitais gerais, que passaram a existir em cada cidade europeia, incumbiram-se de recolher todas as pessoas que não se enquadravam nos padrões estipulados para o trabalho e a configuração familiar. Os loucos eram os pobres, os devassos, os libertinos, etc. Havia, portanto, uma questão moral na concepção da loucura nesses séculos (Foucault 2008; Frayze-Pereira 1994).

Existiam dois sentidos na exclusão social: um ético e outro econômico. Por um lado, a internação não tinha como preocupação a cura, mas sim a culpabilização, a vigilância e a punição de comportamentos considerados inadequados. Devia-se buscar 'um sábio arrependimento' por ser 'louco'. Por outro lado, além do sentido ético, havia um sentido econômico na segregação: nos períodos de crise, a internação justificava-se pela necessidade de higienização das cidades; fora dos períodos de crise, o contingente de pessoas confinadas configurava mão-de-obra barata (Foucault 2008; Frayze-Pereira 1994).

Somente no fim do século XVIII, após a Revolução Francesa (1789-1799), a loucura ganhou a feição de doença e foi apropriada pela Medicina, particularmente pela Psiquiatria, como objeto de conhecimento. O hospital tornou-se, então, um espaço terapêutico, local de tratamento e cura. A despeito de uma suposta objetividade, o contexto no qual a Psiquiatria emergiu estava imbuído de um discurso moral, que percebia o louco como um ser perigoso, que, em função 
de sua 'doença', não conseguia viver conforme as normas sociais. Retirou-se, assim, desse sujeito todo o saber acerca de si próprio e daquilo que seria sua doença, ao mesmo tempo que se delegou esse saber a um especialista. A loucura tornou possível o advento da Psiquiatria, mas é esse campo disciplinar que, paradoxalmente, pretende dizer a 'verdade' sobre a loucura. O fundamento da internação prolongou-se, destarte, nas práticas de hospitalização (Foucault 2008; Frayze-Pereira 1994).

No século XIX, o tratamento dos doentes mentais incluía duchas, banhos frios, chicotadas, máquinas giratórias e sangrias. Outras terapêuticas, como a convulsoterapia, a eletroconvulsoterapia, a lobotomia e a psicofarmacologia, que surgiram no século XX, ensejaram, como contrapartida, o advento de uma crítica radical, inicialmente na Itália, encabeçada por Franco Basaglia, psiquiatra italiano, e, posteriormente, no restante do mundo (Programa de volta para casa. A reforma psiquiátrica e a política de saúde mental 2015; Memória da loucura 2015).

A psiquiatrização das experiências cria uma cultura da normalidade, avessa à diversidade. Há um caráter moral como pano de fundo de uma suposta competência científica. Historicamente, avaliou-se a aptidão para o trabalho, para a convivência, para o casamento, etc. como balizadora da definição de loucura (Foucault 2008; Frayze-Pereira 1994).

No Brasil, alcoólatras, prostitutas, homossexuais, meninas grávidas violentadas por seus patrões, mulheres que haviam perdido a virgindade antes do casamento, entre outras pessoas tidas como desajustadas, foram também confinadas. A marca do holocausto brasileiro foi retratada no Colônia, hospício localizado na cidade mineira de Barbacena, para o qual pessoas como as elencadas foram levadas, no século XX, em trens de doido (Rosa 2005), como ficou conhecido esse meio de transporte, e onde pelo menos 60 mil morreram em situação de extrema barbárie (Arbex 2013).

A concepção da loucura depende, portanto, como anteposto, da caracterização da normalidade em determinado contexto histórico e social. A loucura é relacional, porque é interior à razão, e relativa, por- 
que se inscreve num plano de realidade. A loucura não está localizada no indivíduo, mas revela algo da sociedade em que emerge.

Como consequência dos debates e das ações contra uma visão hospitalocêntrica, foi aprovada na Itália, em 1978, a Lei no 180 , ou Lei da Reforma Psiquiátrica Italiana, também conhecida como Lei Basaglia, que determinou a extinção dos manicômios nesse país e a substituição desse modelo psiquiátrico por outras modalidades de cuidado e assistência. A desinstitucionalização referia-se não apenas à desconstrução dos hospitais psiquiátricos, mas de todo o estigma associado à figura do louco. A Lei Basaglia deu ensejo, no Brasil, à criação e aprovação da Lei no 10.216, de 6 de abril de 2001, também conhecida como Lei da Reforma Psiquiátrica Brasileira.

\section{A reforma psiquiátrica e a construção da política de saúde mental no Brasil}

No mesmo ano da aprovação da Lei da Reforma Psiquiátrica Italiana, em 1978, como consequência das denúncias de que diversos hospitais psiquiátricos exerciam, não uma função terapêutica, mas sim custodial, surgiu um movimento no Brasil que propunha a reforma psiquiátrica, denominado Movimento dos Trabalhadores em Saúde Mental (MTSM), do qual faziam parte profissionais da saúde, pesquisadores, estudantes, usuários de serviços de atenção psicossocial e seus familiares. Esse movimento colocou a loucura na pauta da agenda política. A proposta era a desinstitucionalização do louco e a ressignificação da loucura, ou seja, a substituição da visão do louco como alguém que deve ser enclausurado e da loucura como perigo social pelo debate sobre os direitos humanos e o dever do Estado de oferecer políticas públicas de atenção a essa população. A loucura deixava, então, de ser considerada como um objeto do conhecimento científico e passava a ser encarada a partir da perspectiva dos sujeitos em sofrimento (Brasil 2011b).

Com a reabertura democrática, no início dos anos 1980, e a promulgação da Constituição Federal, em 1988, surgiu uma nova con- 
cepção de saúde, como dever do Estado e direito de todos os cidadãos (Brasil 1988). Os princípios do Sistema Único de Saúde (SUS), já anunciados nos artigos 196 a 200 do texto constitucional, foram regulamentados, em 1990, pela Lei $n^{\circ} 8.080$, de 19 de setembro de 1990, e pela Lei no 8.142, de 28 de dezembro de 1990 (Brasil 1990a; Brasil 1990b).

Nesse mesmo ano, em 1990, o Brasil tornou-se signatário da Declaração de Caracas, que apresentava uma crítica ao modelo hospitalocêntrico na assistência às pessoas com transtornos mentais e preconizava a promoção de modelos centrados na comunidade e dentro de suas redes sociais (Declaração de Caracas 1990). Essa declaração foi um marco das reformas na atenção psicossocial nas Américas.

É nesse cenário que foi proposto o Projeto de Lei no 3.657, em 1989, que dispunha sobre a extinção progressiva dos manicômios e a substituição deles por outros serviços assistenciais mais humanizados. Esse projeto de lei deu ensejo à Lei no 10.216/2001, que dispõe sobre a proteção e os direitos das pessoas com transtornos mentais e redireciona o modelo assistencial em saúde mental. Essa lei sustenta ser responsabilidade do Estado o desenvolvimento da política de saúde mental, a assistência e a promoção de ações de saúde voltadas para pessoas com transtornos mentais, com a devida participação da família e da sociedade (Brasil 2001). A política de saúde mental, por sua vez, aponta para a contínua expansão e consolidação dessa rede de atenção extra-hospitalar, de base comunitária.

Alguns dos serviços atualmente disponíveis em saúde mental são os Centros de Atenção Psicossocial (CAPS), os Serviços Residenciais Terapêuticos (SRT) e o Programa de volta para casa (PVC). Todos eles compõem a Rede de Atenção Psicossocial (RAPS), no âmbito do SUS, conforme a Portaria GM/MS no 3.088, de 23 de dezembro de 2011 (Brasil 2011c).

Segundo o Ministério da Saúde, os CAPS são instituições que oferecem às pessoas com transtornos mentais atendimentos médico e psicológico e, como parte do tratamento, estimulam sua integração 
familiar e social (Mais sobre os serviços disponíveis em saúde mental 2015). Os Núcleos ou Centros de Atenção Psicossocial (NAPS/ CAPS) foram criados oficialmente a partir da Portaria/SNAS no 224, de 29 de janeiro de 1992. Segundo essa portaria, os NAPS/CAPS oferecem atendimento de cuidados intermediários entre o regime ambulatorial e a internação hospitalar e constituem-se em porta de entrada da rede de serviços para as ações relativas à saúde mental. Neles são realizados tanto atendimentos individuais quanto grupais. São feitas também visitas domiciliares, atendimento aos familiares e atividades comunitárias voltadas para a reinserção social das pessoas com transtornos mentais (Brasil 1992).

A Portaria GM/MS no 336, de 19 de fevereiro de 2002, estabelece as modalidades dos Centros de Atenção Psicossocial como CAPS I, CAPS II e CAPS III, definindo-os por ordem crescente de porte/ complexidade e abrangência populacional. Também apresenta os serviços voltados para usuários de álcool e outras drogas, os CAPSad, e aqueles dirigidos a crianças, jovens e adolescentes, os CAPSi (Brasil 2002). Por fim, a Portaria no 245, de 17 de fevereiro de 2005, destina incentivo financeiro para a implantação desses CAPS (Brasil 2005b).

Os SRT são moradias localizadas no espaço urbano direcionadas a pessoas com transtornos mentais graves egressas de hospitais psiquiátricos ou hospitais de custódia e alas de tratamento psiquiátrico que perderam os vínculos familiares e sociais (Mais sobre os serviços disponíveis em saúde mental 2015). A Portaria GM/MS no 106, de 11 de fevereiro de 2000, institui os SRT (Brasil 2000a). Além dessa portaria, a Portaria GM/MS no 1.220 , de 7 de novembro de 2000, que dispõe, entre outros, sobre a criação desses serviços e a atividade profissional do cuidador em saúde, e a Portaria GM/MS n²46, de 17 de fevereiro de 2005, que destina incentivo financeiro para a implantação dos SRT, visam igualmente à criação de residências terapêuticas, destinadas a abrigar essas pessoas e a servir de suporte para a prestação de serviços de atenção à saúde mental substitutivos à internação psiquiátrica prolongada (Brasil 2000b; Brasil 2005a). 
Finalmente, o PVC é um programa de ressocialização que tem por objetivo garantir a assistência, o acompanhamento e a integração social, fora da unidade hospitalar, de pessoas com transtornos mentais, com história de longa internação psiquiátrica (dois anos ou mais de internação ininterruptos). É parte integrante desse programa o auxílio-reabilitação psicossocial, pago ao próprio beneficiário durante um ano, podendo ser renovado, caso necessário (Mais sobre os serviços disponíveis em saúde mental 2015). A Lei no 10.708, de 31 de julho de 2003, institui esse auxílio-reabilitação (Brasil 2003a). A Portaria GM/MS no 2.077, de 31 de outubro de 2003, regulamenta essa lei (Brasil 2003b). Os beneficiários do programa recebiam, mensalmente, em suas contas bancárias, o valor de $\mathrm{R} \$ 240,00$. Esse valor foi reajustado pela Portaria GM/MS n ${ }^{\circ} 1.511$, de 24 de julho de 2013, para $\mathrm{R} \$ 412,00$ (Brasil 2013). O PVC é, ainda, acompanhado por uma Comissão de Acompanhamento, instituída pela Portaria GM/MS n ${ }^{\circ}$ 2.078, de 31 de outubro de 2003 (Brasil 2003c).

\section{A legislação atinente à medida de segurança no Brasil}

Embora exista essa variedade de serviços, regulamentada por leis e portarias, o que se observa é que não existe uma eficácia na mobilização e na atuação do movimento social em saúde mental e da reforma psiquiátrica em prol das pessoas com transtornos mentais em conflito com a lei.

A Lei no 10.216/2001 é superveniente ao Código Penal (Decreto-Lei no 2.848, de 7 de dezembro de 1940). Traz novas perspectivas de interpretação do fenômeno da loucura e de atuação do Estado na implementação da política de saúde mental. Contudo, quando a loucura alia-se ao crime e sobrevém a aplicação da medida de segurança, prevalece no país o entendimento, datado de 1940, de combate à periculosidade mediante o enclausuramento.

A medida de segurança é uma sanção penal infligida a pessoas consideradas inimputáveis ou semi-imputáveis pela Justiça. De acordo com o artigo 26 do Código Penal, inimputável é "[...] o agente que, 
por doença mental ou desenvolvimento mental incompleto ou retardado, era, ao tempo da ação ou da omissão, inteiramente incapaz de entender o caráter ilícito do fato ou de determinar-se de acordo com esse entendimento" (Brasil 1940:s/p). Essa pessoa fica isenta de pena. Ainda segundo o Código Penal, em seu artigo 26, parágrafo único, semi-imputável é "[...] o agente [que], em virtude de perturbação de saúde mental ou por desenvolvimento mental incompleto ou retardado, não era inteiramente capaz de entender o caráter ilícito do fato ou de determinar-se de acordo com esse entendimento" (Brasil 1940:s/p). Essa pessoa pode ter sua sanção reduzida de um a dois terços.

Encaminhadas ao contexto judiciário, no âmbito da medida de segurança, há dois caminhos a serem percorridos por elas: o tratamento ambulatorial, que é realizado nas redes pública e privada de saúde, e a internação em hospital de custódia e tratamento psiquiátrico (HCTP) ou, à falta, em outro estabelecimento correspondente (Brasil 1940). Nesses percursos, o tempo de reclusão, a realização de exames psicológicos e psiquiátricos, cujo objetivo é verificar a cessação de periculosidade, e a existência de parente que as acolha são observados para permitir uma decisão judicial favorável à desinternação condicional, ou seja, a uma desvinculação da Justiça.

Atualmente, merecem destaque três portarias e três resoluções que norteiam as políticas públicas no âmbito da medida de segurança: a Portaria Interministerial $n^{\circ} 1.777$, de 9 de setembro de 2003, a Portaria GM/MS n 94 e a Portaria GM/MS n 95, ambas de 14 de janeiro de 2014; a Resolução n ${ }^{\circ}$, de 4 de maio de 2004, a Resolução $\mathrm{n}^{\circ} 113$, de 20 de abril de 2010, e a Resolução $n^{\circ} 4$, de 30 de julho de 2010, todas em consonância com a Lei n $10.216 / 2001$.

A Portaria Interministerial $n^{\circ} 1.777 / 2003$ aprova o Plano $\mathrm{Na}$ cional de Saúde no Sistema Penitenciário (PNSSP), cujas ações estendem-se aos HCTP ou Alas de Tratamento Psiquiátrico (ATP) (Brasil 2003d). A Portaria GM/MS n 94/2014 institui, no âmbito do SUS, o serviço de avaliação e acompanhamento de medidas terapêuticas aplicáveis ao paciente judiciário, vinculado à Política 
Nacional de Atenção Integral à Saúde das Pessoas Privadas de Liberdade no Sistema Prisional (PNAISP) (Brasil 2014a). Por sua vez, a Portaria GM/MS n 95/2014 dispõe sobre o financiamento desse serviço (Brasil 2014b). Ao propor a criação da Equipe de Avaliação e Acompanhamento de Medidas Terapêuticas Aplicáveis à Pessoa com Transtorno Mental em Conflito com a Lei (EAP), as duas últimas portarias objetivam ampliar o acesso aos serviços e ações de saúde e contribuir para a desinstitucionalização dessa população (Brasil 2014a; Brasil 2014b).

A Resolução n 5/2004, do Conselho Nacional de Política Criminal e Penitenciária (CNPCP), propõe a criação de um programa individualizado de tratamento, concebido por uma equipe multidisciplinar, com vistas à reintegração sócio-familiar. Essa assistência deve incluir ações dirigidas aos familiares e comprometer-se com a construção de projetos voltados para a geração de renda e o desenvolvimento da cidadania (Brasil 2004). A Resolução n 113/2010, do Conselho Nacional de Justiça (CNJ), e a Resolução n 4/2010, do CNPCP, recomendam a adoção da política antimanicomial no que tange à execução da medida de segurança (Brasil 2010a; Brasil 2010b). Esta última dispõe, ainda, sobre as Diretrizes Nacionais de Atenção aos Pacientes Judiciários e Execução da Medida de Segurança e propõe a realização de um acompanhamento psicossocial individualizado e contínuo na rede substitutiva de serviços de saúde mental (Brasil 2010b).

Além dessas portarias e resoluções, o CNJ, em sua Recomendação no 35, de 12 de julho de 2011, preconiza igualmente a adoção da política antimanicomial mediante a criação de um núcleo interdisciplinar de assessoramento aos juízes e de uma equipe, também interdisciplinar, para o acompanhamento psicossocial das pessoas que cumprem medida de segurança, cuja execução deve ser feita na rede de saúde (Brasil 2011d).

Uma experiência inovadora e exitosa, que aboliu definitivamente a ultrapassada figura do manicômio judiciário, com atendimento disponibilizado no SUS, é a do Programa de Atenção Integral ao Louco 
Infrator (Paili), vinculado à Secretária da Saúde do Estado de Goiás. No entanto, no restante do país, observa-se que, embora haja avanços, as portarias, resoluções e recomendação elencadas permanecem inócuas. As pessoas que cumprem medida de segurança, especificamente aquelas que estão na modalidade de internação, permanecem em HCTP ou ATP, que mantêm uma ideologia carcerária. Embora recebam o título de 'hospitais', não se encontram inseridos no sistema de saúde, mas sim na estrutura do sistema prisional. Dessa forma, dois modelos de intervenção social se sobrepõem, um jurídico-punitivo e outro psiquiátrico-terapêutico. Nesse arranjo, a medida de segurança não é regida pelos princípios do SUS, mas pelos princípios da execução penal. E o tratamento das pessoas com transtornos mentais em conflito com a lei, que deveria ser prestado pelo SUS, por uma questão de isonomia e dignidade humana, o é por um HCTP ou por uma ATP. Esse fato reclama uma atenção específica para essas unidades e para a população que atende (Brasil 2011b).

\section{Distrito Federal: legislação e apontamentos preliminares sobre a medida de segurança}

No Distrito Federal (DF), a Lei ${ }^{\circ} 975$, de 12 de dezembro de 1995, embora seja anterior à Lei n⿳ ${ }^{\circ} 10.216 / 2001$, fixa diretrizes para a atenção à saúde mental no mesmo sentido que a lei federal. Segundo a lei distrital, a assistência às pessoas com transtornos mentais deve ser feita mediante serviços substitutivos à internação com o objetivo de (re)integração à sociedade (Brasil 1995).

Especificamente quanto à medida de segurança, na modalidade de internação, não há, no DF, um HCTP, mas sim uma ATP, que é um anexo da Penitenciária Feminina do Distrito Federal (PFDF), localizada na Região Administrativa do Gama. Contrariamente ao que é legalmente recomendado, a ATP/DF não somente não está integrada à rede de cuidados do SUS, como se encontra vinculada à Subsecretaria do Sistema Penitenciário (Sesip), da Secretaria de Estado de Justiça e Cidadania do Distrito Federal (Sejus). 
Quanto à modalidade de tratamento ambulatorial, há dezenas de serviços disponíveis nas redes pública e privada de saúde, com destaque para os CAPS. Não há nenhuma residência terapêutica no DF.

\section{Metodologia}

Este estudo teve como objetivo conhecer o perfil das pessoas que cumprem medida de segurança no DF. Entre 1º de outubro de 2013 e 29 de julho de 2014, foi realizada uma pesquisa quanti-qualitativa mediante a análise documental de todos os processos e prontuários concernentes a essa população, com exceção de 9 casos, referentes a pessoas que cumpriam medida de segurança na modalidade de internação. Esses 9 processos não puderam ser analisados ou porque não haviam chegado à Vara de Execuções Penais (1) ou por estarem no Ministério Público (3), no Instituto Médico Legal (4) ou de posse do advogado do sentenciado (1) durante o período supracitado. Foram, portanto, analisados 164 processos e prontuários de um total de 173.

É importante ressaltar que a Constituição Federal, no artigo 5, inciso XXXIII, e no artigo 93, inciso IX, bem como o Código de Processo Penal, de 3 de outubro de 1941, no artigo 792, asseguram que todos os atos processuais do Poder Judiciário sejam, em regra, públicos, ressalvados os casos expressamente previstos em lei (Brasil 1988; Brasil 1941). Tal entendimento é reforçado, ainda, pela Lei no 12.527 , de 18 de novembro de 2011 (Brasil 2011a).

Como estratégias de proteção aos dados contidos nos processos e prontuários, foram adotados os seguintes procedimentos: 1 . assinatura, por parte da equipe de pesquisa, de um termo de responsabilidade pelo uso de informações e cópias de documentos para fins de pesquisa; e 2. realização da pesquisa documental dos processos e prontuários nas dependências do Tribunal de Justiça do Distrito Federal e dos Territórios (TJDFT), o que visava a assegurar o sigilo e a confidencialidade dos dados. Ademais, nenhuma informação que pudesse identificar as pessoas que cumpriam medida de segurança no DF, seus familiares ou mesmo os profissionais do TJDFT foi 
utilizada. Buscou-se, assim, garantir o anonimato em todas as fases da pesquisa.

Para a coleta de dados, foi elaborado um instrumento de pesquisa com 26 questões com o objetivo de levantar o perfil sóciodemográfico das pessoas que cumpriam medida de segurança no DF. As questões foram divididas em dois blocos: um concernente à identificação (sexo, idade, naturalidade, situação conjugal, raça/ cor, escolaridade e profissão) e outro referente à situação processual (incidência penal, diagnóstico, origem da medida de segurança, sentença, prazo mínimo para o cumprimento da sentença, última avaliação da Seção Psicossocial da Vara de Execuções Penais (VEP) do TJDFT, último laudo do Instituto Médico Legal (IML) e tempo de cumprimento da sentença) da população anteposta. Esse instrumento foi avaliado e validado pelos profissionais da saúde da VEP do TJDFT antes do início da coleta de dados.

Compunham a equipe de pesquisa sete estudantes da Universidade de Brasília, que foram previamente treinados. Durante o mês de setembro de 2013, também anteriormente ao início da coleta de dados, foi realizado um pré-teste tanto para verificar, e posteriormente sanar, eventuais dúvidas dos membros da equipe de pesquisa quanto para averiguar possíveis inadequações do instrumento às fontes de dados, os processos e os prontuários, para, assim, haver uma reformulação das questões finais da pesquisa.

Durante todo o período de realização da pesquisa, todos os dados coletados foram revisados por dois pesquisadores. Aqueles processos extintos durante o curso da pesquisa foram excluídos. Em outras palavras, o universo dos processos e prontuários analisados condiz com a totalidade das pessoas que cumpriam medida de segurança que não tiveram a sua sentença extinta até o final de julho de 2014.

Para a sistematização dos dados, foi criado um dicionário das variáveis que permitiu organizar as informações coletadas. Após a verificação da integridade e da consistência dos dados, as variáveis foram codificadas numericamente. $O$ programa utilizado para montar o ban- 
co de dados, visualizar e analisar os resultados foi o software de análise estatística SPSS (Statistical Package for the Social Sciences).

Todos os aspectos éticos preconizados pela Resolução n 466, de 12 de dezembro de 2012, do Conselho Nacional de Saúde do Ministério da Saúde, que regulamenta estudos que envolvem seres humanos no país, foram observados e assegurados (Brasil 2012). A pesquisa foi avaliada e aprovada pelo Comitê de Ética em Pesquisa do Instituto de Ciências Humanas (CEP/IH) da Universidade de Brasília (CAAE: 16027013.5.0000.5540).

\section{Resultados}

. Situação da população em medida de segurança no Distrito Federal

Cumpriam medida de segurança no DF, no período de $1^{\circ}$ de outubro de 2013 a 29 de julho de 2014, 173 indivíduos. Dos indivíduos cujos processos e prontuários foram analisados, $41 \%$ estavam na internação; 40\%, no tratamento ambulatorial; e 20\%, na desinternação condicional.

A situação da população em medida de segurança por sexo indica que $87 \%$ eram homens e $13 \%$, mulheres (Tabela 1 ).

Tabela 1

Situação da população em MS por sexo - DF, 2013/2014

\begin{tabular}{|lcc|}
\hline Situação da população em MS & Homens & Mulheres \\
\hline Internação & 60 & 7 \\
Tratamento ambulatorial & 52 & 13 \\
Desinternação condicional & 30 & 2 \\
Total & 142 & 22 \\
\hline
\end{tabular}

Fonte: Estudo sobre a medida de segurança no Distrito Federal, 2013/14. 
Os dados mostram, ainda, que a idade média da população em medida de segurança era 38 anos: 36 na internação, 40 no tratamento ambulatorial e 36 na desinternação condicional.

Os indivíduos eram provenientes das cinco regiões do Brasil: do Norte, dos estados do Pará (1) e de Tocantins (2); do Nordeste, dos estados de Alagoas (1), da Bahia (10), do Ceará (4), do Maranhão (7), da Paraíba (4), de Pernambuco (4), do Piauí (8) e do Rio Grande do Norte (2); do Sul, dos estados do Paraná (1) e de Santa Catarina (1); do Sudeste, dos estados de Minas Gerais (10), do Rio de Janeiro (4) e de São Paulo (2); com prevalência da região Centro-Oeste, do Distrito Federal (91) e do estado de Goiás (11). Em 1 caso, não havia a informação concernente à naturalidade do indivíduo.

Em relação à situação conjugal, as pessoas que cumpriam medida de segurança eram, em sua maioria, solteiras (81\%), seguidas das casadas/unidas (12\%), divorciadas/separadas (6\%) e viúvas (1\%).

Quanto à raça/cor, as pessoas eram, em sua maioria, pardas (76\%). $9 \%$ eram pretas e $7 \%$, brancas. $4 \%$ tiveram uma classificação diferente das categorias disponibilizadas no instrumento de coleta de dados. E, em 3\% dos casos, não havia informação sobre a raça/cor. Verifica-se que, neste quesito, 16 pessoas foram classificadas em duas categorias: em 6 casos, a pessoa foi considerada preta e parda; em 5 casos, branca e parda; em 4 casos, parda e outra raça/cor; e, em 1 caso, preta e outra raça/cor. Uma explicação possível para um mesmo indivíduo ser enquadrado em mais de uma categoria deve-se ao fato de que essas pessoas foram heteroclassificadas pelo IML em circunstâncias diversas e, provavelmente, por pessoas distintas. É importante salientar, ainda, que as opções branca, preta, parda, amarela e indígena são aquelas disponibilizadas pelo Instituto Brasileiro de Geografia e Estatística (IBGE). Ao considerar a classificação desse instituto, segundo a qual pretos e pardos compõem o grupo de pessoas negras, o total de pessoas negras em medida de segurança no DF era de $85 \%$.

A maioria das pessoas que cumpriam medida de segurança tinha o Ensino Fundamental Incompleto (61\%). 14\% tinham o 
Ensino Fundamental Completo, 12\% tinham o Ensino Médio, 9\% eram analfabetas, 2\% tinham o Ensino Superior e 0,6\% tinha PósGraduação. Em 1\% dos casos, não havia informação sobre este quesito.

As profissões refletem a escolaridade apresentada: $45 \%$ dos indivíduos eram trabalhadores dos serviços, vendedores do comércio em lojas e mercados; 20\% eram trabalhadores da produção de bens e serviços industriais; $4 \%$ eram trabalhadores em serviços de reparação e manutenção; $3 \%$ eram trabalhadores agropecuários, florestais e da pesca; $2 \%$ eram técnicos de nível médio; $1,8 \%$ era profissional das ciências e das artes; igualmente $1,8 \%$ era membro das Forças Armadas, policiais e bombeiros; e 0,6\% era trabalhador de serviços administrativos. Em 13\% dos casos, o item 'não se aplica' foi assinalado. Essa categoria é composta por: aposentados (6\%), estudantes (3\%), pessoas que nunca trabalharam (3\%) e pessoa sem profissão/ ocupação (1\%). Em 5\% dos casos, a profissão foi categorizada como 'não identificada'. Trata-se de desempregados (2\%), autônomo $(1 \%)$, empresário $(0,6 \%)$, funcionário público $(0,6 \%)$, cujas profissões não foram identificadas nos processos e prontuários, e pessoa sem profissão definida $(0,6 \%)$. Finalmente, em $4 \%$ dos casos, não havia informação sobre este quesito. É importante mencionar que as categorias usadas são aquelas contidas na Classificação Brasileira de Ocupações (Brasil 2010).

Em relação à incidência penal, a maior parte dos crimes (38\%) foi cometida contra o patrimônio. Em seguida, aparecem os crimes contra a pessoa (27\%), seguidos dos crimes contra a dignidade sexual (10\%). Há, ainda, outros crimes do Código Penal, que configuram 9\% dos crimes registrados, e infrações penais de outros Códigos e/ ou Leis, que somam $16 \%$ do total. Dentre os crimes predominantes, ou seja, aqueles cometidos contra o patrimônio, destacam-se o furto $(18 \%)$ e o roubo (15\%) nas modalidades tentada e consumada (Tabela 2). É relevante mencionar que, neste quesito, um mesmo indivíduo pode se enquadrar em mais de uma categoria. 
Tabela 2

Infrações penais cometidas pela população em MS - DF, 2013/2014

\begin{tabular}{|l|l|}
\hline INFRAÇÕES & \\
\hline
\end{tabular}

Crimes contra a pessoa

Homicídio simples

$26,9 \%$

Homicídio qualificado

Tentativa de homicídio simples

$0,6 \%$

Tentativa de homicídio qualificado

$6,1 \%$

$2,6 \%$

$3,2 \%$

Aborto provocado por terceiro

$0,3 \%$

Lesão corporal

$5,0 \%$

Lesão corporal de natureza grave

$0,3 \%$

Lesão corporal seguida de morte

$0,0 \%$

Rixa

$0,3 \%$

Injúria

$0,9 \%$

Ameaça

$6,1 \%$

Sequestro e cárcere privado

$0,9 \%$

Violação de domicílio

$0,6 \%$

Crimes contra o patrimônio

$38,0 \%$

Furto

Furto qualificado

$6,1 \%$

$6,1 \%$

Tentativa de furto

Tentativa de furto qualificado

$3,8 \%$

Roubo

Tentativa de roubo

Extorsão

Dano qualificado

Tentativa de dano qualificado

$2,3 \%$

$10,5 \%$

$4,7 \%$

$0,6 \%$

$1,8 \%$

$0,3 \%$

Apropriação indébita

$0,3 \%$

Estelionato

$0,6 \%$

Outras fraudes

$0,3 \%$

Receptação

$0,6 \%$

Crimes contra o sentimento religioso e contra o respeito aos mortos

Destruição, subtração ou ocultação de cadáver

$0,6 \%$

Vilipêndio a cadáver

$0,3 \%$

$0,3 \%$

Crimes contra a dignidade sexual

Estupro

$9,9 \%$

Tentativa de estupro

$1,2 \%$

$0,9 \%$

Atentado violento ao pudor

$4,4 \%$

Tentativa de atentado violento ao pudor

$0,3 \%$

Estupro de vulnerável

$1,2 \%$

Corrupção de menores

$1,2 \%$

Ato obsceno

$0,9 \%$ 
Crimes contra a família

$0,3 \%$

Subtração de incapazes

$0,3 \%$

Crimes contra a incolumidade pública

$0,3 \%$

Incêndio

$0,3 \%$

Crimes contra a fé pública

Falsificação de documento público

$1,2 \%$

Falsidade ideológica

$0,3 \%$

Falsa identidade

$0,6 \%$

$0,3 \%$

Crimes contra a administração pública

$7,0 \%$

Peculato

$0,3 \%$

Resistência

$2,6 \%$

Desobediência

$0,9 \%$

Desacato

$1,8 \%$

Coação no curso do processo

$0,3 \%$

Desobediência a decisão judicial sobre perda ou suspensão de direito

$1,2 \%$

Crimes da Lei Antidrogas

$2,0 \%$

Consumo de drogas

$0,6 \%$

Tráfico de drogas

$1,5 \%$

Crimes do Estatuto do Desarmamento

$3,5 \%$

Porte ilegal de arma de fogo de uso permitido

Disparo de arma de fogo

$1,2 \%$

Posse ou porte ilegal de arma de fogo de uso restrito

$0,6 \%$

Crimes da Lei Maria da Penha

$5,3 \%$

Violência doméstica e familiar contra a mulher

Crimes do Código de Trânsito Brasileiro

$1,8 \%$

Homicídio culposo na direção de veículo automotor

$0,6 \%$

Lesão corporal culposa na direção de veículo automotor

$0,6 \%$

Condução de veículo automotor com capacidade psicomotora alterada

Direção de veículo automotor sem a Habilitação

$0,3 \%$

$0,3 \%$

Crimes do Estatuto da Criança e do Adolescente

Submissão a vexame ou a constrangimento de criança ou adolescente

$0,3 \%$

$0,3 \%$

\section{Contravenções Penais}

Porte de arma fora de casa, sem licença da autoridade

Prática de vias de fato contra alguém

Excitação de animal, expondo a perigo a segurança alheia

Perturbação do trabalho ou do sossego alheios

$0,3 \%$

Importúnio de modo ofensivo ao pudor

$0,3 \%$

Perturbação da tranquilidade por motivo reprovável

$0,3 \%$

TOTAL

$100 \%$ $(n=342)$

Fonte: Estudo sobre a medida de segurança no Distrito Federal, 2013/14. 
Quanto ao diagnóstico, há uma prevalência dos transtornos mentais e comportamentais devidos ao uso de álcool e outras drogas (27\%), seguidos pelos casos de esquizofrenia (16\%), transtornos de personalidade (13\%), retardo mental (11\%), psicose não-orgânica não especificada (8\%), transtornos afetivos uni ou bipolares (6\%), epilepsia (4\%), transtornos delirantes persistentes (3\%), transtornos de preferência sexual (2\%) e transtornos mentais orgânicos (2\%). $9 \%$ dos diagnósticos não se enquadravam na Classificação Estatística Internacional de Doenças e Problemas Relacionados com a Saúde (CID), publicada pela Organização Mundial da Saúde (OMS), referência usada para categorizar os diagnósticos das pessoas com transtornos mentais em conflito com a lei (http://www.medicinanet.com.br/cid10.htm 2015). É importante salientar que, também neste quesito, um mesmo indivíduo pode se enquadrar em mais de uma categoria.

Do total, $71 \%$ foram considerados inimputáveis pela Justiça e 26\%, semi-imputáveis. Em 2\% dos casos, não havia informação quanto à origem da medida de segurança.

No que diz respeito à sentença, como anteposto, $41 \%$ dos indivíduos receberam a medida de segurança na modalidade de internação, $40 \%$ foram encaminhados ao tratamento ambulatorial e $20 \%$ estavam na desinternação condicional. Neste quesito, foram, ainda, discriminados aqueles indivíduos que, na internação, encontravamse na condição de reinternados. Do total de 67 indivíduos, 50 foram internados pela primeira vez e 17 estavam na reinternação.

Em $70 \%$ dos casos, o prazo mínimo para o cumprimento da medida de segurança foi de 1 ano. Em 7\%, esse tempo foi de 2 anos. E, em 13\%, o prazo mínimo foi de 3 anos. Em 9\%, foi assinalada a opção 'outros' e, em $1 \%$, não havia informação sobre este quesito. $O$ prazo mínimo é o tempo determinado pelo juiz para que haja uma nova avaliação do sentenciado para uma possível desvinculação da Justiça. Segundo o Código Penal, o prazo mínimo deve ser de um a três anos (Brasil 1940). 
A última avaliação da Seção Psicossocial da VEP do TJDFT indicava que, em 35\% dos casos, as pessoas que cumpriam medida de segurança contavam com apoio familiar. Em 4\% dos casos, não havia referência familiar. Em $22 \%$ dos casos, a situação de saúde era considerada estável. Em contrapartida, em 18\% dos casos, a situação de saúde era tida como comprometida. Em $10 \%$ dos casos, havia encaminhamento para a desinternação condicional. Em igualmente $10 \%$ dos casos, a classificação foi diferente das categorias disponibilizadas no instrumento de coleta de dados, sendo, portanto, assinalado o item 'outros'.

Por sua vez, o último laudo do IML apontava que, em 31\% dos casos, as pessoas que cumpriam medida de segurança contavam com apoio familiar. Em 5\% dos casos, não havia referência familiar. Em $16 \%$ dos casos, a situação de saúde era considerada estável. Por outro lado, em 31\% dos casos, a situação de saúde era tida como comprometida. Em $8 \%$ dos casos, havia encaminhamento para a desinternação condicional. Finalmente, em $9 \%$ dos casos, a categorização foi 'outros', pelo fato de as informações contidas no laudo serem diferentes daquelas apresentadas.

É importante salientar que o acompanhamento das pessoas que cumprem medida de segurança no DF é contínuo e que os números apresentados correspondem a um recorte das avaliações feitas tanto pela Seção Psicossocial da VEP do TJDFT quanto pelo IML, quando da análise dos processos e prontuários. Ademais, é relevante mencionar que, igualmente neste quesito, um mesmo indivíduo pode se enquadrar em mais de uma categoria.

A média de tempo de cumprimento da medida de segurança foi de 3 anos na internação, 1 ano no tratamento ambulatorial e 5 anos na desinternação condicional. O menor tempo encontrado de cumprimento da sentença foi de 16 dias na internação, 7 dias no tratamento ambulatorial e 204 dias na desinternação condicional. O maior tempo encontrado de cumprimento da sentença foi de 13 anos e 8 meses na internação, 3 anos e 9 meses no tratamento ambulatorial e 16 anos e 2 meses na desinternação condicional. O tempo foi 
calculado a partir da diferença entre a data da coleta dos dados e a data de início do cumprimento da medida de segurança, o que significa que foi feito um recorte. Ou seja, as sentenças estavam em curso quando da fixação do tempo. No caso do menor tempo encontrado, por exemplo, é possível que os dias tenham sido cumpridos por pessoas que haviam acabado de receber a sentença quando da coleta de dados. Ademais, é importante lembrar que as pessoas que estavam na desinternação condicional passaram antes pela internação. Segundo o Código Penal, são duas as modalidades de medida de segurança, a internação e o tratamento ambulatorial. A desinternação é a desvinculação da Justiça, que ocorre de modo condicional, ou seja, no decurso de um ano, a pessoa que a recebe é acompanhada para verificar se, aos olhos da Justiça, houve cessação de sua periculosidade (Brasil 1940).

Assim, considerando que um ano é o tempo estipulado para a efetiva liberação da Justiça, após o recebimento da desinternação condicional, dos 32 indivíduos que a receberam, 5 estavam com a data provável de extinção da sentença expirada.

\section{- Dados comparativos sobre a custódia e o tratamento psiquiátrico no Distrito Federal: o censo de 2011}

Em 2013, foram divulgados dados sobre a custódia e o tratamento psiquiátrico em todo o Brasil e, particularmente, no DF referentes a 2011. Na ocasião, foram fornecidos dados concernentes à população da ATP/DF, seja em medida de segurança, seja em situação temporária de internação (Diniz 2013).

As informações ora apresentadas tiveram como referência basilar esse censo. $\mathrm{O}$ intuito da coleta e análise de novos dados concernentes à medida de segurança no DF é atualizar as informações obtidas dois anos antes sobre a medida de segurança na modalidade de internação e aprofundar dados sobre a população em medida de segurança em tratamento ambulatorial e desinternação condicional.

Para comparar as novas informações com aquelas de 2011, tomaremos apenas os dados do censo atinentes à população em medi- 
da de segurança, não em situação temporária de internação. Quanto às informações de 2013/2014, serão usadas apenas aquelas relativas à internação. As lacunas desta comparação dever-se-ão a dois fatores: 1. em 2011, foram identificadas pessoas em tratamento ambulatorial (1) e desinternação condicional (3) na ATP/DF, situações atípicas, tendo em vista que esse é um espaço de cumprimento da medida de segurança na modalidade de internação; e 2. além da ATP/DF, outros serviços, públicos e privados, do DF acolhem pessoas que recebem a medida de segurança na modalidade de internação. Assim, os dados de 2013/2014 que dizem respeito à internação extrapolam os muros da ATP/DF.

A população total em 2011 era de 83 pessoas. Em 2013/2014, esse número caiu para 76 pessoas, das quais 67 processos e prontuários foram analisados.

Em 2011, havia 81 homens e 2 mulheres. Já em 2013/2014, 60 homens e 7 mulheres cumpriam medida de segurança na modalidade de internação.

Os dados mostram uma população mais jovem em 2011: a idade média era 34 anos. Em 2013/2014, esse número subiu para 36 anos. É preciso considerar, no entanto, que o início do cumprimento da internação por 34 pessoas, em 2013/2014, data de 2011 ou de anos anteriores. Ou seja, se essas pessoas tinham 34 anos em 2011 e continuaram internadas em 2013/2014, elas passaram a ter $36 \mathrm{em} 2013$ (Tabela 3).

Tabela 3

Situação da população em MS na modalidade de internação - DF, 2011 e 2013/2014

\begin{tabular}{|lcc|}
\hline & 2011 & $2013 / 2014$ \\
\hline Homens & 81 & 60 \\
Mulheres & 2 & 7 \\
Total & 83 & 67 \\
Idade média & 34 anos & 36 anos \\
\hline
\end{tabular}

Fontes: Diniz, Debora. A custódia e o tratamento psiquiátrico no Brasil: censo 2011. Estudo sobre a medida de segurança no Distrito Federal, 2013/14. 
Em relação à situação conjugal, as pessoas que cumpriam medida de segurança na ATP/DF em 2011 eram, em sua maioria, solteiras (67), seguidas das casadas/unidas (13) e divorciadas/separadas (3). Em 2013/2014, as pessoas internadas eram, em sua maioria, igualmente solteiras (59), seguidas das casadas/unidas (4), divorciadas/separadas (2) e viúvas (2). Verifica-se, assim, que a situação conjugal dessa população não sofreu grandes alterações ao longo dos anos. A maioria das pessoas era solteira em ambas as pesquisas.

Quanto à raça/cor, em 2011, as pessoas eram, em sua maioria, pardas (49). 18 eram pretas e 14, brancas. 2 tiveram uma classificação diferente das categorias disponibilizadas pelo censo. Em 2013/2014, as pessoas também eram, em sua maioria, pardas (55). 5 eram brancas e 4 , pretas. 2 tiveram uma classificação diferente das categorias disponibilizadas no instrumento de coleta de dados. Em 1 caso, não havia informação sobre a raça/cor. Assim, o total de pessoas negras manteve-se predominante tanto em 2011 (67) quanto em 2013/2014 (59). Esses dados permitem afirmar também que, em 2013/2014, a proporção de pessoas negras tornou-se ainda mais elevada.

Em 2011, a maioria da população era composta por indivíduos com o Ensino Fundamental Incompleto (44). 17 pessoas tinham o Ensino Fundamental Completo, 11 eram analfabetas e 7 tinham o Ensino Médio. Em 4 casos, não havia informação quanto à escolaridade. Em 2013/2014, a maioria das pessoas tinha, igualmente, o Ensino Fundamental Incompleto (42). Em igual proporção, 8 tinham o Ensino Fundamental Completo e 8 eram analfabetas. 6 tinham o Ensino Médio e 1 tinha o Ensino Superior. Em 2 casos, não havia informação sobre este quesito (Gráfico 1). Observa-se, assim, que não houve modificações consideráveis quanto à escolaridade ao longo dos anos.

No que diz respeito à profissão, todas as pessoas de ambas as pesquisas encontravam-se em idade ativa. A população, em 2011, compunha majoritariamente o item 'não se aplica' (20). Nessa categoria, como anteposto, foram incluídos aposentados, estudantes, pessoas que nunca trabalharam e pessoas sem profissão/ocupação. Ademais, 
19 indivíduos eram trabalhadores da produção de bens e serviços industriais; 15 eram trabalhadores dos serviços, vendedores do comércio em lojas e mercados; 8 eram trabalhadores em serviços de reparação e manutenção; 5 eram trabalhadores agropecuários, florestais e da pesca; 1 era profissional das ciências e das artes; e 1 era trabalhador de

\section{Gráfico 1}

Escolaridade da população em MS na modalidade de internação - DF, 2011 e 2013/2014

\begin{tabular}{|lcc|}
\hline Escolaridade & 2011 & 2013/2014 \\
\hline Analfabeto & 11 & 8 \\
Fundamental incompleto & 44 & 42 \\
Fundamental completo & 17 & 8 \\
Médio & 7 & 6 \\
Superior & 0 & 1 \\
Total & 79 & 65 \\
\hline
\end{tabular}

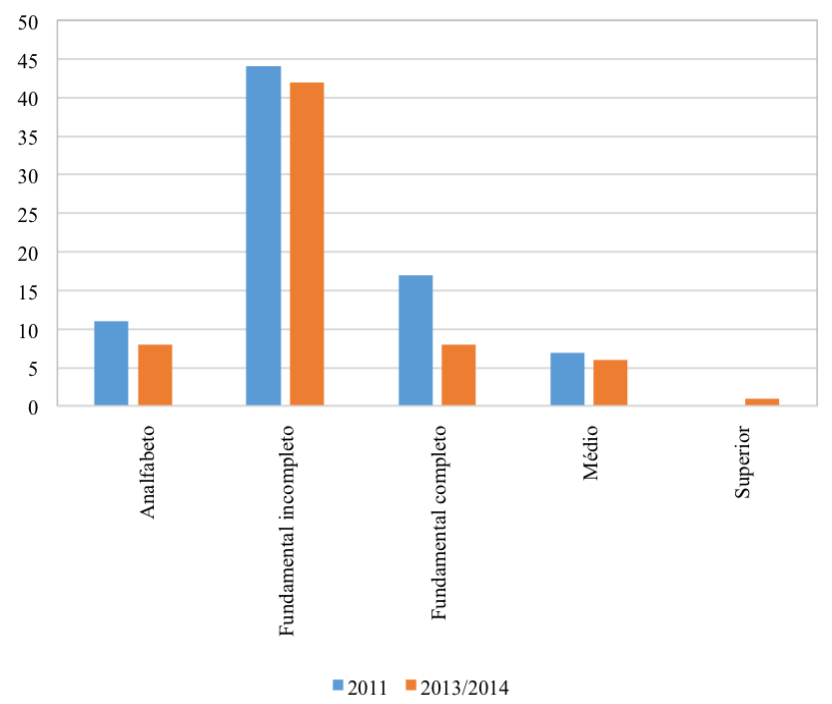

Fontes: Diniz, Debora. A custódia e o tratamento psiquiátrico no Brasil: censo 2011. Estudo sobre a medida de segurança no Distrito Federal, 2013/14. 
serviços administrativos. Em 8 casos, a profissão foi categorizada como 'não identificada'. Nesse item, como igualmente mencionado, foram incluídos desempregados, autônomos, empresários, funcionários públicos, cujas profissões não foram identificadas, e pessoas sem profissão definida. Por fim, em 6 casos, não havia informação sobre a profissão.

As três primeiras categorias também foram as mais encontradas em 2013/2014, mas com predominância diferenciada: 33 indivíduos eram trabalhadores dos serviços, vendedores do comércio em lojas e mercados; 10 eram trabalhadores da produção de bens e serviços industriais; e 11 enquadravam-se no item 'não se aplica'. As demais profissões encontradas em 2013/2014 foram as seguintes: trabalhadores em serviços de reparação e manutenção (4); trabalhadores agropecuários, florestais e da pesca (1); e técnicos de nível médio (1). Em 5 casos, a profissão foi categorizada como 'não identificada'. Finalmente, em 2 casos, não havia informação sobre este quesito.

As infrações penais mais recorrentes em ambas as pesquisas foram os crimes contra o patrimônio (47\% tanto em 2011 quanto em 2013/2014). Em seguida, aparecem os crimes contra a pessoa (35\% em 2011 e 28\% em 2013/2014). Em 2011, sobrevêm os crimes contra a dignidade sexual (10\%), seguidos de outros crimes, não listados (4\%), das infrações penais de outros Códigos e/ou Leis (2\%) e de outros crimes do Código Penal (1\%). Em 2013/2014, aparecem, após os crimes contra o patrimônio e os crimes contra a pessoa, em ordem de prevalência, as infrações penais de outros Códigos e/ou Leis (9\%) e, em igual proporção, os crimes contra a dignidade sexual (8\%) e outros crimes do Código Penal (8\%). É importante reiterar que, neste quesito, um mesmo indivíduo pode se enquadrar em mais de uma categoria, ou seja, pode cumprir medida de segurança por duas ou mais infrações penais cometidas.

Em 2011, 6 pessoas que cumpriam medida de segurança na ATP/ DF cometeram infrações penais em sua rede familiar ou doméstica. Embora a comparação entre as duas pesquisas seja precária devido ao fato de o número de casos 'sem informação' em 2011 ser elevado 
(8), superando a categoria 'sim', que afirmava o cometimento de infração no âmbito familiar ou doméstico, é possível afirmar que, em 2013/2014, a proporção de indivíduos que cometeram esse tipo de infração aumentou, passando para 13. Em 2013/2014, não houve casos 'sem informação'. Um dado que corrobora a hipótese do aumento da aplicação da medida de segurança nessa situação é o surgimento de casos de violência doméstica e familiar contra a mulher em crimes da Lei Maria da Penha, que não existiam em 2011 e foram encontrados na pesquisa de 2013/2014, constituindo 9 infrações penais.

Finalmente, e talvez resida aqui o principal achado desta nova pesquisa, em 2013/2014, há uma prevalência dos transtornos mentais e comportamentais devidos ao uso de álcool e outras drogas, diferentemente do principal diagnóstico encontrado em 2011, não somente no DF, como também no restante do país, a esquizofrenia.

Em 2011, a esquizofrenia (31\%) foi seguida pelos casos de transtornos mentais e comportamentais devidos ao uso de álcool e outras drogas (20\%), retardo mental (12\%), transtornos de personalidade $(4 \%)$, transtornos afetivos uni ou bipolares (2\%) e transtornos de preferência sexual (1\%). 1\% dos casos não se enquadrava na CID. Além disso, em $28 \%$ dos casos, não havia informação sobre este quesito.

Em 2013/2014, os transtornos mentais e comportamentais devidos ao uso de álcool e outras drogas (27\%) foram seguidos pelos casos de esquizofrenia (15\%) e transtornos de personalidade (15\%), em igual proporção, retardo mental (11\%), psicose não-orgânica não especificada (7\%), transtornos afetivos uni ou bipolares (5\%) e epilepsia (5\%), também em igual proporção, transtornos delirantes persistentes (4\%), transtornos de preferência sexual (3\%) e, por fim, transtornos mentais orgânicos (1\%). Em 8\% dos casos, não havia adequação à classificação da CID. É relevante mencionar que, também neste quesito, um mesmo indivíduo pode se enquadrar em mais de uma categoria.

Um aprofundamento da reflexão sobre o novo perfil encontrado de pessoas internadas, bem como em tratamento ambulatorial e desinternação condicional, será realizado a seguir. 


\section{Discussão}

Embora os NAPS/CAPS devam constituir-se em porta de entrada da rede de cuidado para as ações relativas à saúde mental, a lacuna na oferta desses serviços tem levado à falta de tratamento adequado e necessário a pessoas com transtornos mentais e à consequência drástica de viabilizar o acesso a esses serviços somente pela via judicial, após o cometimento de um crime e o encaminhamento à Justiça para o cumprimento de uma das modalidades da medida de segurança. A porta de entrada da atenção à saúde mental passa a ser o Poder Judiciário, e não o Poder Executivo, que tem negligenciado o tratamento das pessoas com transtornos mentais antes do agravamento de seu estado de saúde.

Mesmo após a aplicação da medida de segurança, a negligência estatal persiste, com falhas na oferta de serviços, como os SRT, apresentados, e os Centros de Convivência e Cultura, que deveriam substituir, via de regra, a internação.

A imobilidade do Poder Executivo na implementação desses serviços substitutivos encontra respaldo no Código Penal. As pessoas consideradas inimputáveis ou semi-imputáveis pela Justiça recebem uma absolvição imprópria. Em outras palavras, no âmbito da medida de segurança, a culpabilidade dessas pessoas, existente nos séculos XVII e XVIII, é substituída pela noção de periculosidade. Essa noção fornece o pano de fundo para justificar a aplicação da medida de segurança em locais que seguem uma ideologia carcerária, sem limite definido de duração. Ora, ao deixar-se de punir uma ação praticada no passado mediante a aplicação de uma pena por tempo determinado e propor-se um tratamento que deve agir sobre um comportamento futuro, sem prazo para término, pode-se condenar as pessoas com transtornos mentais em conflito com a lei a viverem reclusas ad aeternum (Brasil 2011b). A periculosidade dessas (e de todas as outras) pessoas pode efetivamente cessar? Ademais, em casos de transtornos mentais incuráveis, seria justificada uma prisão perpétua? $\mathrm{O}$ uso dessa noção 
torna-se ainda mais injustificado se, observada a realidade, constatase, como foi verificado no DF, que a maior parte das infrações penais cometidas pelas pessoas com transtornos mentais em conflito com a lei concerne a crimes contra o patrimônio, dentre os quais destacamse o furto e o roubo.

Como anteriormente mencionado, o Código Penal prevê um prazo mínimo para o cumprimento da medida de segurança e a reavaliação do sentenciado de um a três anos (Brasil 1940). Entretanto, não há um prazo máximo. "A internação, ou o tratamento ambulatorial, será por tempo indeterminado, perdurando enquanto não for averiguada [...] a cessação de periculosidade” (Brasil 1940:***). Não obstante a ausência da determinação de um prazo máximo, a Constituição Federal, em seu artigo 5 XLVII, b, determina que não haja penas de caráter perpétuo no Brasil (Brasil 1988). Ademais, o Supremo Tribunal Federal (STF) e o Superior Tribunal de Justiça (STJ) firmaram o entendimento de que o prazo máximo da medida de segurança não deve ultrapassar 30 anos, em analogia ao disposto no artigo 75 do Código Penal para penas privativas de liberdade (Brasil 1940). Finalmente, o STJ concluiu que o tempo máximo de cumprimento da medida de segurança não pode ser superior ao limite máximo da pena abstratamente prevista para o delito cometido.

Contudo, em consonância com a crítica anteposta ao Código Penal e a necessidade de que a medida de segurança seja aplicada à luz da Lei $n^{\circ}$ 10.216/2001, há inúmeros casos em que essa orientação não é seguida. Para se ater a um dado referente ao Brasil, divulgado pelo censo realizado em 2011 sobre a custódia e o tratamento psiquiátrico, 21\% da população encarcerada cumprem pena além do tempo previsto (Diniz 2013). Especificamente no DF, conforme a pesquisa realizada em 2013/2014, foi verificado que 3\% dos indivíduos que cumpriam medida de segurança estavam com a data de extinção da sentença expirada e permaneciam, portanto, internados.

Estado falha, destarte, na assistência às pessoas com transtornos mentais antes do cometimento de um delito. A entrada nos servi- 
ços de atenção psicossocial não ocorre mediante a atuação do Poder Executivo, mas sim do Poder Judiciário, após a aplicação de uma das modalidades da medida de segurança. Nesse contexto, as pessoas, já tachadas de loucas, são consideradas também criminosas. A esse duplo estigma soma-se, ainda, o preconceito por serem, em sua maioria, negras.

Ademais, essa população é amiúde abandonada pela família. Os HCTP e as ATP, onde a modalidade de internação é cumprida no país, são instituições totais, locais apartados da sociedade, marcados pela mortificação das pessoas que neles se encontram. As indignidades são físicas e simbólicas. Às barreiras edificadas por muros, arames farpados ou grades soma-se a perda da identidade. Se as pessoas com transtornos mentais em conflito com a lei tinham família antes de receberem a medida de segurança, esse vínculo é frequentemente quebrado. Há, assim, a supressão de lares reais ou potenciais (Goffman 2010). Isso pode ser verificado pelo fato de que as pessoas que cumpriam medida de segurança no DF eram, em sua maioria, solteiras.

Além do tempo de reclusão e de exames, pareceres psicológicos e psiquiátricos, cujo objetivo é verificar a cessação de periculosidade, como observado nas avaliações da Seção Psicossocial da VEP do TJDFT e nos laudos do IML, no DF, um dos requisitos para a desvinculação da Justiça é a existência de um parente que se responsabilize pelas pessoas com transtornos mentais em conflito com a lei. Se a família não quer (ou não pode) receber essas pessoas ou se essas pessoas já não têm família, seria o Estado o incumbido a assisti-las (Quinaglia Silva 2014). Como anteposto, o Estado não as assume antes do cometimento de um delito. Tampouco, disponibiliza serviços de cuidado após a aplicação da medida de segurança. Nesse ciclo vicioso, essa população fica, então, abandonada. Em termos práticos, parte dessas pessoas é mantida enclausurada por falta de ambientes apropriados para acolhê-las.

Segundo a Lei no 10.216/2001, já mencionada, a internação deve ser indicada como último recurso terapêutico. $\mathrm{O}$ tratamento deve vi- 
sar, como finalidade permanente, à reinserção social. Em seu artigo $5^{\circ}$, essa lei prevê, ainda, a criação de política específica de alta planejada e reabilitação psicossocial assistida nos casos de grave dependência institucional, decorrente de um quadro clínico severo ou da ausência de suporte social (Brasil 2001). NAPS/CAPS, SRT, Centros de Convivência e Cultura, entre outros serviços, deveriam, portanto, ser disponibilizados pelo Estado, como igualmente exposto.

Uma atenção especial deveria ser dada ao aprimoramento de políticas específicas de atenção psicossocial destinadas às pessoas dependentes de álcool e outras drogas. Como foi verificado, o principal diagnóstico encontrado entre as pessoas que cumpriam medida de segurança no DF foram os transtornos mentais e comportamentais devidos ao uso de álcool e outras drogas. Uma estratégia seria investir nos CAPSad, anteriormente citados, voltados para o atendimento de pessoas com esse perfil.

Especificamente os hospitais de custódia e as alas de tratamento psiquiátrico, como a ATP/DF, oferecem um tratamento inadequado às pessoas que cumprem medida de segurança na modalidade de internação, não apenas por aproximarem-se de cárceres (a ATP/DF, por exemplo, está, de fato, localizada em uma penitenciária, como anteposto), mas também pela impossibilidade de elaboração de projetos terapêuticos singulares em um espaço que abarca transtornos variegados. Pode haver um efetivo tratamento em um ambiente em que convivem pessoas com diagnósticos que vão da esquizofrenia ao retardo mental? A Lei no 10.216/2001, que determina que as pessoas com transtornos mentais em conflito com a lei devem ser atendidas no SUS, vem sendo, portanto, paulatinamente descumprida. Também as portarias, resoluções e recomendação elencadas, concernentes às políticas públicas no âmbito da medida de segurança, não têm tido contrapartida real. E esses locais de depósito humano persistem em reproduzir o paradoxo histórico da medida de segurança no Brasil: embora devam ser locais de tratamento, constituem-se em prisões; em vez de cuidado, conferem punição. 
Solteiras, negras, com baixa escolaridade e profissões que exigem pouca qualificação, diagnosticadas com transtornos mentais e comportamentais devidos ao uso de álcool e outras drogas e tendo cometido furto ou roubo, este é o perfil das pessoas que cumpriam medida de segurança no DF entre 2013 e 2014. O sentido da exclusão social, outrora subjacente à discriminação de pobres, devassos e libertinos, prevalece hodiernamente, ora voltado para as pessoas que cumprem medida de segurança. As naus dos loucos (Foucault 2008; Frayze-Pereira 1994) ou os trens de doido (Rosa 2005; Arbex 2013) contemporâneos continuam a encaminhar para os HCTP e as ATP aqueles que não se enquadram em um padrão de normalidade socialmente estipulado. A noção de periculosidade associada a eles perpetua o enclausuramento em hospitais-presídios. Enquanto perdurarem não somente os manicômios judiciários, como também os nossos manicômios mentais, essa outra face da clausura (Pelbart 1990), centenas (ou milhares, se considerado o universo mais amplo do Brasil) de pessoas continuarão esquecidas e silenciadas. Conhecer esse perfil enseja, assim, desconstruir preconceitos, questionar a (ir)responsabilidade do Estado e revisitar a política de saúde mental.

\section{Notas}

1 As autoras agradecem à equipe de profissionais da saúde da Seção Psicossocial da VEP do TJDFT, especialmente à Annamaria Maistri, à Carla Faria Machado, à Caroline Quinaglia A. C. S. Brandi, à Elizabeth dos Santos Pinho, à Jacqueline Reis Demes, à Lílian Cherulli de C. I. da Costa, à Raquel Gomes Pinto Manzini e à Sabrina Barbosa Alexandre, a disponibilidade e a atenção dispensadas na realização desta pesquisa. Também agradecem aos estudantes Andressa da Silva Palmeira, İsadora Gonçalves Bonifácio, Lays Reis Ribeiro, Mônica Oliveira da Cruz, Rayssa de Paula Dantas Trajano, Rian Pessoa Vieira e Sthefânya Shabryny Cavalcante Regis Moreira o empenho na coleta dos dados nos processos e prontuários.

2 Érica Quinaglia Silva participou do planejamento e da coordenação do estudo, análise dos dados, redação e revisão do texto. Marília Calegari participou da sistematização e análise dos dados, redação e revisão do texto. 


\section{Referências}

ARBEX, Daniela. 2013. Holocausto Brasileiro. São Paulo: Geração Editorial.

DINIZ, Debora. 2013. A Custódia e o Tratamento Psiquiátrico no Brasil: censo 2011. Brasília: LetrasLivres, Editora Universidade de Brasília.

FOUCAULT, Michel. 2008. História da Loucura. São Paulo: Perspectiva.

FRAYZE-PEREIRA, João Augusto. 1994. O Que é Loucura. São Paulo: Brasiliense.

GOFFMAN, Erving. 2010. Manicômios, Prisões e Conventos. São Paulo: Perspectiva.

PELBART, Peter P. 1990. "Manicômio mental: a outra face da clausura." In LANCETTI. A. (ed.): Saúde Loucura 2, pp.130-138. São Paulo: Editora Hucitec.

QUINAGLIA SILVA, É. \& BRANDI, C. 2014. "'Essa medida de segurança é infinita ou tem prazo de vencimento?': interlocuções e desafios entre o Direito e a Psicologia no contexto judiciário." Ciência $\mathfrak{E}$ Saúde Coletiva, 19(9):3947-3954.

ROSA, João G. 2005. Primeiras Estórias. Rio de Janeiro: Nova Fronteira.

\section{Documentos}

BRASIL. Código de Processo Penal (Decreto-Lei n 3.689, de 3 de outubro de 1941). 1941. Diário Oficial da União.

Código Penal (Decreto-Lei no 2.848, de 7 de dezembro de 1940). 1940. Diário Oficial da União.

. Constituição da República Federativa do Brasil de 1988. 1988. Diário Oficial da União.

. Lei no 10.216, de 6 de abril de 2001. 2001. Dispõe sobre a proteção e os direitos das pessoas portadoras de transtornos mentais e redireciona o modelo assistencial em saúde mental. Diário Oficial da União.

. Lei no 10.708 , de 31 de julho de 2003. 2003a. Institui o auxílio-reabilitação psicossocial para pacientes acometidos de transtornos mentais egressos de internações. Diário Oficial da União.

Lei $\mathrm{n}^{\circ}$ 12.527, de 18 de novembro de 2011. 2011a. Regula o acesso a informações previsto no inciso XXXIII do art. $5^{\circ}$, no inciso II do $\S 3^{\circ}$ do art. 37 e no $\S 2^{\circ}$ do art. 216 da Constituição Federal; altera a Lei $n^{\circ} 8.112$, de 11 de dezembro de 1990; revoga a Lei $n^{\circ} 11.111$, de 5 de maio de 2005, e dispositivos da Lei n 8.159 , de 8 de janeiro de 1991; e dá outras providências. Diário Oficial da União.

. Lei no 8.080, de 19 de setembro de 1990. 1990a. Dispõe sobre as condições para a promoção, proteção e recuperação da saúde, a organização e o funcionamento dos serviços correspondentes e dá outras providências. Diário Oficial da União. 
BRASIL. Lei no 8.142, de 28 de dezembro de 1990. 1990b. Dispõe sobre a participação da comunidade na gestão do Sistema Único de Saúde (SUS) e sobre as transferências intergovernamentais de recursos financeiros na área da saúde e dá outras providências. Diário Oficial da União.

. Lei n 975 , de 12 de dezembro de 1995. 1995. Fixa diretrizes para a atenção à saúde mental no Distrito Federal e dá outras providências. Diário Oficial da União.

. Ministério do Trabalho e Emprego (MTE). Secretaria de Políticas Públicas de Emprego (SPPE). Classificação Brasileira de Ocupações. 2010. Brasília: MTE, SPPE. 3.ed.

. Ministério Público Federal (MPF) e Procuradoria Federal dos Direitos do Cidadão (PFDC). Parecer sobre medidas de segurança e Hospitais de Custódia e Tratamento Psiquiátrico sob a perspectiva da Lei no 10.216/2001. 2011b. Brasília.

. Portaria GM/MS n 106, de 11 de fevereiro de 2000. 2000a. Institui os serviços residenciais terapêuticos. Diário Oficial da União.

Portaria GM/MS no 1.220, de 7 de novembro de 2000. 2000b. Diário Oficial da União.

. Portaria GM/MS n 1.511, de 24 de julho de 2013. 2013. Reajusta o valor do auxílio-reabilitação psicossocial, instituído pela Lei $\mathrm{n}^{\circ} 10.708$, de 31 de julho de 2003. Diário Oficial da União.

. Portaria GM/MS no 2.077, de 31 de outubro de 2003. 2003b. Dispõe sobre a regulamentação da Lei no 10.708, de 31 de julho de 2003, nos termos de seu artigo $8^{\circ}$. Diário Oficial da União.

. Portaria GM/MS no 2.078, de 31 de outubro de 2003. 2003c. Institui a Comissão de Acompanhamento do Programa "De volta para casa". Diário Oficial da União.

Portaria GM/MS no 246, de 17 de fevereiro de 2005. 2005a. Destina incentivo financeiro para implantação de serviços residenciais terapêuticos e dá outras providências. Diário Oficial da União.

Portaria GM/MS no 3.088, de 23 de dezembro de 2011. 2011c. Institui a Rede de Atenção Psicossocial para pessoas com sofrimento ou transtorno mental e com necessidades decorrentes do uso de crack, álcool e outras drogas, no âmbito do Sistema Único de Saúde (SUS). Diário Oficial da União.

. Portaria GM/MS no 336, de 19 de fevereiro de 2002. 2002. Estabelece CAPS I, CAPS II, CAPS III, CAPSi e CAPSad. Diário Oficial da União.

. Portaria GM/MS nº 94, de 14 de janeiro de 2014. 2014a. Institui o serviço de avaliação e acompanhamento de medidas terapêuticas aplicáveis à pessoa com transtorno mental em conflito com a Lei, no âmbito do Sistema Único de Saúde (SUS). Diário Oficial da União.

. Portaria GM/MS n 95, de 14 de janeiro de 2014. 2014b. Dispõe sobre o financiamento do serviço de avaliação e acompanhamento às medidas terapêuticas aplicáveis ao paciente judiciário, no âmbito do Sistema Único de Saúde (SUS). Diário Oficial da União. 
BRASIL. Portaria Interministerial $n^{\circ}$ 1.777, de 9 de setembro de 2003. 2003d. Diário Oficial da União.

. Portaria $\mathrm{n}^{\circ}$ 245, de 17 de fevereiro de 2005. 2005b. Destina incentivo financeiro para implantação de Centros de Atenção Psicossocial e dá outras providências. Diário Oficial da União.

. Portaria/SNAS no 224, de 29 de janeiro de 1992. 1992. Diário Oficial da União.

. Recomendação no 35, de 12 de julho de 2011. 2011d. Dispõe sobre as diretrizes a serem adotadas em atenção aos pacientes judiciários e a execução da medida de segurança. Diário Oficial da União.

. Resolução $n^{\circ} 113$, de 20 de abril de 2010. 2010a. Dispõe sobre o procedimento relativo à execução de pena privativa de liberdade e de medida de segurança e dá outras providências. Diário Oficial da União.

. Resolução n 4, de 30 de julho de 2010. 2010b. Dispõe sobre as Diretrizes Nacionais de Atenção aos Pacientes Judiciários e Execução da Medida de Segurança. Diário Oficial da União.

. Resolução no 466, de 12 de dezembro de 2012, do Conselho Nacional de Saúde do Ministério da Saúde. 2012. Diário Oficial da União.

Resolução $n^{0}$ 5, de 4 de maio de 2004. 2004. Dispõe a respeito das Diretrizes para o cumprimento das Medidas de Segurança, adequando-as à previsão contida na Lei $n^{\circ} 10.216$, de 6 de abril de 2001. Diário Oficial da União.

DECLARAÇÃO de Caracas, de 14 de novembro de 1990.

MAIS Sobre os Serviços Disponíveis em Saúde Mental. (http://portalsaude.saude. gov.br/index.php/cidadao/acoes-e-programas/conte-com-a-gente/leia-maisconte-com-a-agente/284-mais-sobre-os-servicos-disponiveis-em-saude-mental; acesso em 8/11/2015).

MEMÓRIA da Loucura. (www.ccs.saude.gov.br/memoria\%20da\%20loucura/ mostra/tratamentos.html; acesso em 8/11/2015).

PROGRAMA de Volta para Casa. A Reforma Psiquiátrica e a Política de Saúde Mental. (www.ccs.saude.gov.br/vpc/reforma.html; acesso em 8/11/2015).

\begin{abstract}
Security measures are sanctions applied to people who are considered mad and criminal by Justice. This quantitative and qualitative research, through the analysis of processes and records, made it possible to know the profile of this population in the Federal District (Brazil). $81 \%$ were single, $85 \%$ were black, $61 \%$ had incomplete primary education and $45 \%$ worked in services or sales in shops and markets. In addition, $27 \%$ had mental and behavioral disorders due to use of alcohol and other drugs.
\end{abstract}


Regarding crimes, 38\% were committed against property. Finally, 3\% of the people had the termination date of the sentence expired. The notion of danger associated with this population perpetuates the confinement in prison-hospitals. Knowing these people entails desconstructing prejudices and revisiting the mental health policy.

Keywords: Crime, Madness, Security Measures, Psychiatric Reform, Mental Health Policy.

Recebido em outubro de 2018.

Aprovado em dezembro de 2018. 